\title{
Obliquity of the Stapes in Otosclerosis: A New Radiological Sign
}

\author{
Veluswamy Anand $^{1} \quad$ H. N. Udayabhanu ${ }^{1} \quad$ B. Siva Subramaniam ${ }^{2}$
}

${ }^{1}$ Department of Otorhinolaryngology and Head and Neck Surgery,

Address for correspondence Dr. Veluswamy Anand, MS, Department MCV Memorial ENT Trust Hospital, Pollachi, Tamil Nadu, India

${ }^{2}$ Department of Radiology, SRL, Diagnostic-Hitech Scan Center, of Otorhinolaryngology and Head and Neck Surgery, MCV Memorial Coimbatore, Tamil Nadu, India ENT Trust Hospital, Palaghat Road 115, Pollachi, TN 642001, India (e-mail: anand@entanand.com).

Int Arch Otorhinolaryngol 2016;20:94-98.

\begin{abstract}
Keywords

- obliquity

- otosclerosis

- stapes

- temporal bone

Introduction Observing the obliquity of stapes by closely scrutinizing the HRCT temporal bone in otosclerosis revealed a reliable and consistent finding. This finding can add to the existing radiological criteria in diagnosis of otosclerosis.

Objective The objective of this study is to establish the obliquity of stapes in otosclerosis by radiological measurements using HRCT temporal bone by comparing: (a) the distance between the horizontal (tympanic) segment of facial nerve and stapes head in otosclerotic ears (study group) with non-otosclerotic ears (control group); and (b) the angle subtended by stapes with promontory in the study and control groups. Methods This is a prospective study performed after the institutional Ethics Committee clearance (IEC 3/2013).

Results An increased mean distance between the horizontal segment of facial nerve and stapes head in otosclerotic patients (i.e., $2.49 \mathrm{~mm}+/-0.24 \mathrm{~mm}$ SD), when compared with the non-otosclerotic patients (i.e., $1.46 \mathrm{~mm}+\mid-0.16 \mathrm{~mm} \mathrm{SD}$ ) is noted. There is a change in angle (i.e., $64.550+/-7.190 \mathrm{SD}$ ) subtended by the stapes toward the promontory in otosclerotic ears when compared with that of controls (i.e., $99.700+/-40$ SD). We applied the Mann-Whitney $U$ non-parametric test and considered $p$ value of $<0.0001$ highly significant.

Conclusions Obliquity of stapes in otosclerosis referred to as a "Pisa" sign by the senior author has diagnostic value as a new radiological sign in imaging of otosclerosis. This obliquity explains the torsional effect of otosclerosis on the ossicular chain. The findings correlate with late complications and failures in stapes surgery.
\end{abstract}

\section{Introduction}

Otosclerosis is a two stage, metabolic bone remodelling process of the otic capsule characterized by bone resorption (otospongiosis) and recalcification (otosclerosis). The term otosclerosis was coined by Adam Politzer in $1894 .^{1}$ Anson and Bast etiologically related the histologically unstable cartilage in the fissular region to the development of otosclerosis. A mass of newly formed bone remodels itself and becomes an

received

December 10, 2015

accepted

December 16, 2015

published online

March 9, 2016
DOI http://dx.doi.org/ 10.1055/s-0036-1579743. ISSN $1809-9777$. active focus of otosclerosis. ${ }^{2-4}$ Malleoincudal dislocation may occur when there is regrowth of otosclerotic bone above the oval window. Secondary torsional stresses on the stapes pulling the incus down is believed to be responsible for Malleoincudal dislocation, which can be diagnosed by High Resolution Computed Tomography (HRCT) temporal bone imaging. ${ }^{5}$ After stapes surgery, the biologically remodeled incus would revert back to its original position due to the absence of torsional forces of stapes and subsequent pull by
Copyright $\odot 2016$ by Thieme Publicações License terms Ltda, Rio de Janeiro, Brazil

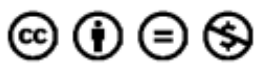


the superior incudal ligament. This can lead to late complications in stapes surgery. The purpose of this study is to objectively evaluate the obliquity of stapes toward promontory and the torsional effect of otosclerosis on the stapes and rest of the ossicular chain by radiological imaging. Though observed by surgeons, no radiological study has been done to evaluate and utilize this critical information.

\section{Objectives}

The objectives of this study are to document the obliquity and inferior displacement of stapes observed during stapedotomy surgery for otosclerosis. We performed a radiological evaluation to a) calculate the distance between the tympanic segment of facial nerve and stapes head and b) to establish the torsional effect of otosclerosis on stapes and ossicular chain by measuring the change in angle subtended by the stapes with the promontory in both the study and control groups.

\section{Method}

This is a prospective study done in our center from January 2013 to December 2014. This study was comprised of 20 patients divided into two groups. The study group consisted of 10 otosclerotic patients and the control group of 10 non-otosclerotic patients who presented to us with sudden sensorineural hearing loss. All patients with sudden sensorineural hearing loss (SSNHL) underwent tympanometry with reflex study. Only those with either ipsilateral or contralateral reflex positive were selected to exclude any otosclerosis in this group. After getting informed consent from patients and clearance from institutional ethics committee (IEC 3/2013), we examined patients radiologically by HRCT temporal bone imaging. The scans were obtained with identical protocols. With the patient lying in the neutral position, we performed HRCT temporal bone imaging in both axial and coronal planes with $1 \mathrm{~mm}$ slice thickness with table feed of $1 \mathrm{~mm}$, perpendicular to the orbito meatal line using Siemens Somotome Duo (Siemens, Erlangen, Germany). We took high resolution temporal bone CT scans of $1 \mathrm{~mm}$ contiguous coronal sections with no gap between two slices at the level of lateral semicircular canal. The same radiologist read the images. Measurement of the length and also the angle were done only in the coronal plane using syngo software.

\section{Length}

A straight line was drawn to measure distance between the mid horizontal (tympanic) segment of facial nerve and stapes head in coronal sections using syngo software in both the study and control groups (-Fig. 1).

\section{Angle}

The angle subtended by the stapes with promontory in the otosclerotic and non-otosclerotic patients was measured using syngo software between two lines, one from the oval window to head of stapes and second line from the promontory to stapes head (-Fig. $\mathbf{2}$ ).

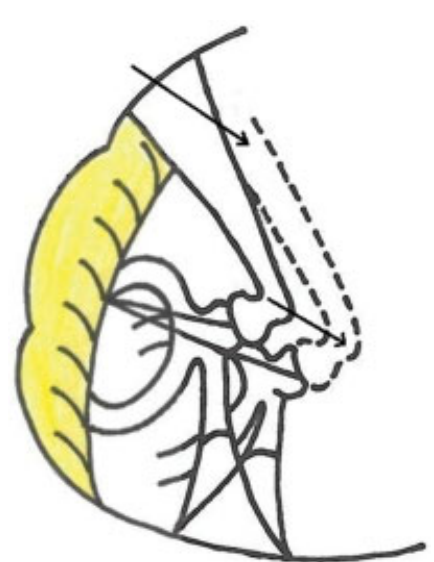

Fig. 1 Illustration showing the increase in length from facial nerve to stapes head due to obliquity of stapes in otosclerosis (dotted line).

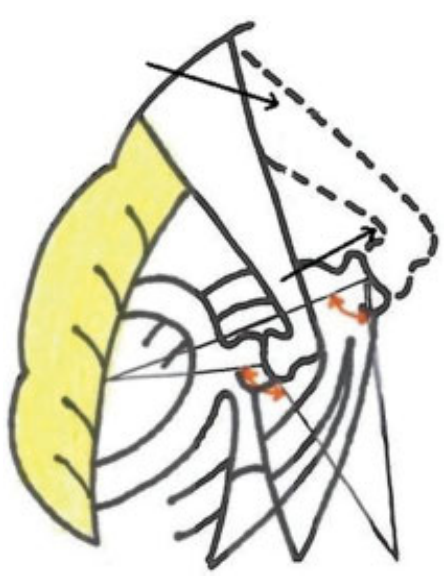

Fig. 2 Illustration showing change in angle due to obliquity of stapes in otosclerosis (dotted line).

\section{Result}

We compared the radiological measurements obtained in the otosclerotic and non-otosclerotic patients (i.e., SSNHL) and ran a statistical analysis with SPSS 17.0 software using the Mann-Whitney U non-parametric test. The mean distance between the facial nerve and the stapes head in High resolution CTscans, $1 \mathrm{~mm}$ contiguous coronal sections, taken at the level of the lateral semicircular canal was $2.49 \mathrm{~mm}$ $+/-0.24 \mathrm{~mm}$ SD in otosclerotic ears and $1.46 \mathrm{~mm}+/-0.16$ $\mathrm{mm}$ SD in non-otosclerotic ears. In the otosclerosis subjects, the mean angle measured was $64.55^{\circ}+/-7.19^{\circ} \mathrm{SD}$, whereas in the non-otosclerotic ears it was $99.70^{\circ}+1-4^{\circ} \mathrm{SD}$. The Man-Whitney $\mathrm{U}$ non-parametric test showed that the test statistic value was greater than the table value for length and angle measurements in both the groups and the $p$ value was highly significant at level $<0.0001$. This indicates a torsional effect and downshift of the stapes toward the promontory (-Tables 1, 2, 3 and -Figs. 3-8). 
Table 1 HRCT temporal bone measurements in otosclerotic patients

\begin{tabular}{|l|l|l|}
\hline Serial & Distance (in mm) & Angle (in degrees) \\
\hline 1 & 2.90 & $52.95^{\circ}$ \\
\hline 2 & 2.40 & $69^{\circ}$ \\
\hline 3 & 2.40 & $64.18^{\circ}$ \\
\hline 4 & 2.90 & $69^{\circ}$ \\
\hline 5 & 2.23 & $65.399^{\circ}$ \\
\hline 6 & 2.22 & $55.60^{\circ}$ \\
\hline 7 & 2.40 & $72^{\circ}$ \\
\hline 8 & 2.60 & $65^{\circ}$ \\
\hline 9 & 2.33 & $57.55^{\circ}$ \\
\hline 10 & 2.60 & $74.845^{\circ}$ \\
\hline
\end{tabular}

Table 2 HRCT temporal bone measurements in nonotosclerotic patients

\begin{tabular}{|l|l|l|}
\hline Serial & Distance (in mm) & Angle (in degrees) \\
\hline 1 & 1.30 & $103^{\circ}$ \\
\hline 2 & 1.20 & $99^{\circ}$ \\
\hline 3 & 1.72 & $100.029^{\circ}$ \\
\hline 4 & 1.52 & $93.729^{\circ}$ \\
\hline 5 & 1.60 & $101^{\circ}$ \\
\hline 6 & 1.40 & $101^{\circ}$ \\
\hline 7 & 1.59 & $93.217^{\circ}$ \\
\hline 8 & 1.54 & $97.369^{\circ}$ \\
\hline 9 & 1.48 & $105.325^{\circ}$ \\
\hline 10 & 1.30 & $103.45^{\circ}$ \\
\hline
\end{tabular}

\section{Discussion}

Histologically, otosclerosis is characterized by a wave of abnormal bone remodelling with resorption of the otic capsule bone and replacement with a hyper cellular woven bone that, over a long time, undergoes further remodelling, resulting in sclerotic mosaic architecture. ${ }^{6}$ The most common area of stapes fixation is the anterior crus in the region of the embryonic fissula antefenestram. ${ }^{7-9}$ Fissula antefenestram is unique to humans. ${ }^{10}$ Because of the metamorphosis of the lining cartilage, fissulae in general and large fissulae in particular are areas of histological instability. ${ }^{2}$ An underlying genetic defect of COL1A1 gene in collagen metabolism results in the generation of an unstable extracellular matrix with a high propensity for remodelling. ${ }^{11}$ It is quite clear from the above that biological remodelling is the norm in oval window area in otosclerosis.

Other researchers have observed that, in otosclerosis, differences in the tilt of stapes superstructure and malposition of the incus are common. ${ }^{12}$ The obliquity of the stapes toward the promontory and the torsional effect of otosclerosis
Table 3 Mann-Whitney U Test

\begin{tabular}{|c|c|c|c|c|}
\hline \multicolumn{5}{|l|}{ i) Ranks } \\
\hline & Group* & $\mathrm{N}$ & $\begin{array}{l}\text { Mean } \\
\text { Rank }\end{array}$ & $\begin{array}{l}\text { Sum of } \\
\text { Ranks }\end{array}$ \\
\hline CT.OTO.L & 1 & 10 & 15.50 & 155.00 \\
\hline CT.NON-OTO.L & 2 & 10 & 5.50 & 55.00 \\
\hline \multicolumn{2}{|l|}{ Total } & 20 & - & - \\
\hline OTO.ANG & 1 & 10 & 5.50 & 55.00 \\
\hline NON-OTO.ANG & 2 & 10 & 15.50 & 155.00 \\
\hline \multicolumn{2}{|l|}{ Total } & 20 & - & - \\
\hline \multicolumn{5}{|c|}{ ii) Test Statistics ${ }^{a}$} \\
\hline \multicolumn{2}{|l|}{ Test } & \multicolumn{2}{|c|}{$\begin{array}{l}\text { Distance } \\
\text { statistic } \\
\text { value for } \\
\text { both } \\
\text { groups }\end{array}$} & $\begin{array}{l}\text { Angle statistic } \\
\text { value for } \\
\text { both groups }\end{array}$ \\
\hline \multicolumn{2}{|l|}{ Mann-Whitney U } & \multicolumn{2}{|c|}{0.000} & 0.000 \\
\hline \multicolumn{2}{|l|}{ Wilcoxon W } & \multicolumn{2}{|c|}{55.000} & 55.000 \\
\hline \multicolumn{2}{|l|}{ Z } & \multicolumn{2}{|c|}{-3.790} & -3.782 \\
\hline \multicolumn{2}{|c|}{ Asymp. Sig. (2-tailed) } & \multicolumn{2}{|c|}{0.000} & 0.000 \\
\hline \multicolumn{2}{|c|}{$\begin{array}{l}\text { Exact Sig. [2* (1-tailed } \\
\text { Sig.)] }\end{array}$} & \multicolumn{2}{|c|}{$0.000^{\mathrm{b}}$} & $0.000^{\mathrm{b}}$ \\
\hline \multicolumn{2}{|c|}{ Exact Sig. (2-tailed) } & \multicolumn{2}{|c|}{0.000} & 0.000 \\
\hline \multicolumn{2}{|c|}{ Exact Sig. (1-tailed) } & \multicolumn{2}{|c|}{0.000} & 0.000 \\
\hline \multicolumn{2}{|l|}{ Point Probability } & \multicolumn{2}{|c|}{0.000} & 0.000 \\
\hline
\end{tabular}

Abbreviations: CT. OTO.L, CT otosclerosis length; CT.NON-OTO, CT nonotosclerosis length; OTO.ANG, otosclerosis angle; NON.OTO ANG, nonotosclerosis angle; Asymp., asymptomatic; Sig., signal.

${ }^{*}$ Group 1, Otosclerosis; Group 2, Non-otosclerosis.

${ }^{\mathrm{a} G r o u p i n g ~ V a r i a b l e: ~ g r o u p . ~}$

${ }^{\mathrm{b}}$ Not corrected for ties.

on the ossicular chain is understood by comparing the distance between the stapes and facial nerve canal as well as the angulations of stapes with promontory in both study and control groups in this study. The torsional effect of otosclerosis, leading to the obliquity of stapes, also affects the incus and rest of the ossicular chain. These observations have not yet been objectively evaluated and documented.

\section{Radiology of Otosclerosis}

The usual radiological findings in case of otosclerosis is low attenuation in fissula antefenestram, thickening of the oval window membrane, plaque or new bone formation, and reduced surface area of the stapes. ${ }^{5}$ The mean Hounsfield unit (HU) values in the area anterior to the oval window (A-OW) are significantly lower in otosclerosis than in others. Based on receiver operating characteristic (ROC) analysis, the cut-off $\mathrm{HU}$ value in A-OW was 2,187.3 HU. ${ }^{13}$ Malleoincudal dislocation can occur, secondary to torsional stresses, particularly when there is growth of otosclerotic bone above the oval window, which is diagnosed by CT criteria. ${ }^{5}$ In addition to these, there is increased distance between the stapes head and the horizontal segment of 


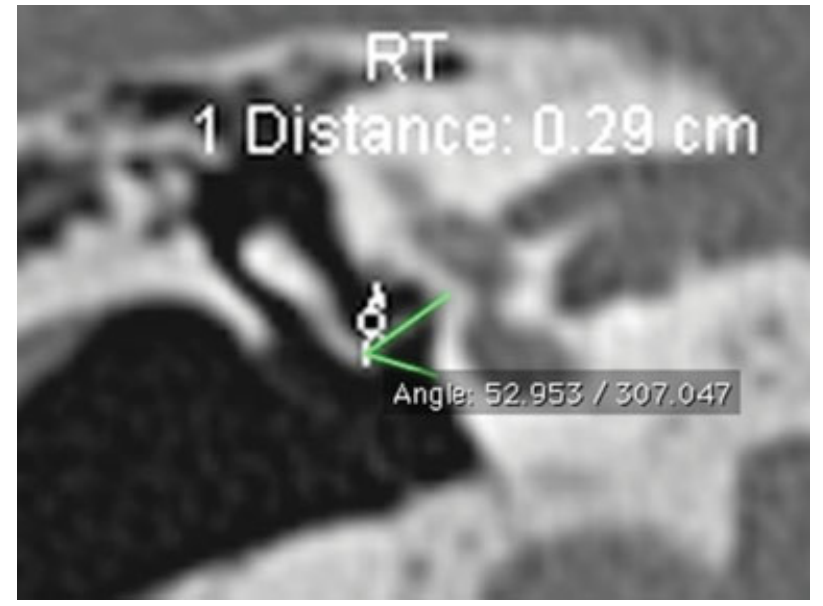

Fig. 3 HRCT Temporal bone coronal image showing length and angle measured in Otosclerotic patient.

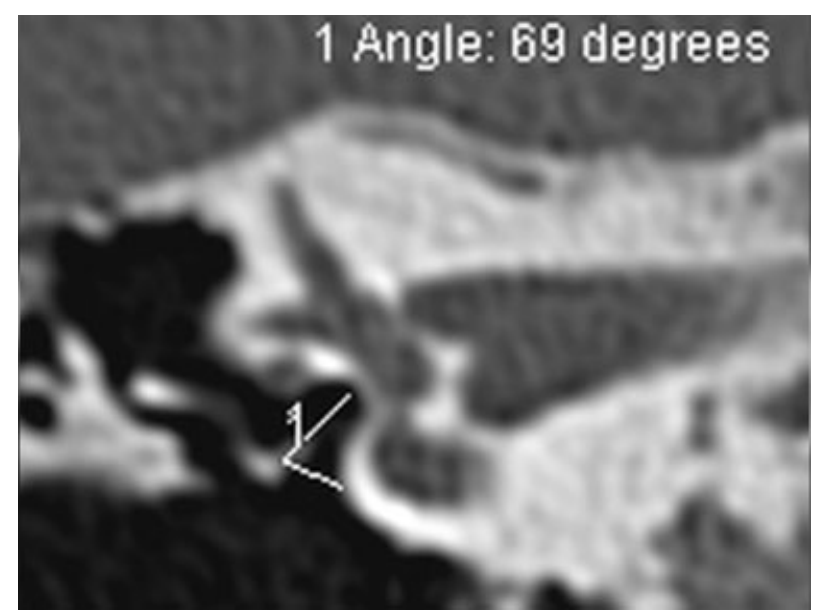

Fig. 4 HRCT Temporal bone coronal image showing angle measured in otosclerotic patient.

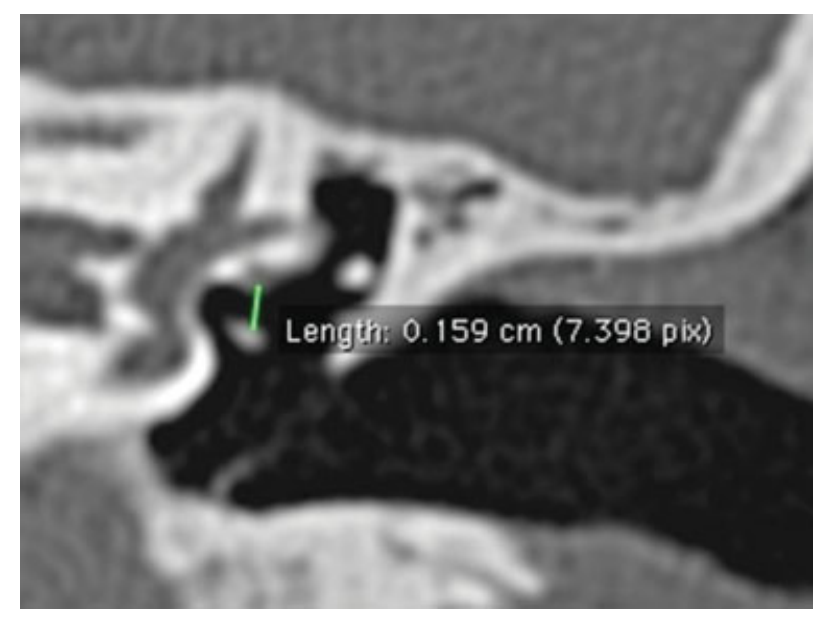

Fig. 5 HRCT Temporal bone length measured in non-otosclerotic patient.

facial nerve in otosclerosis when compared with the nonotosclerotic patients. There is also a difference in the angle subtended by the stapes with promontory between otosclerotic and non-otosclerotic patients. These findings documented in our study after HRCT temporal bone imaging can be used as new

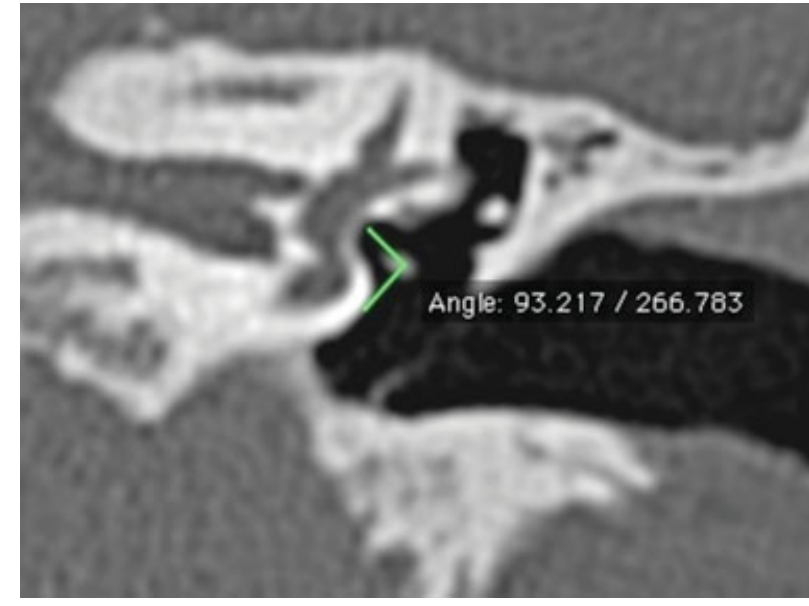

Fig. 6 HRCT Temporal bone showing angle measured in non-otosclerotic patient.

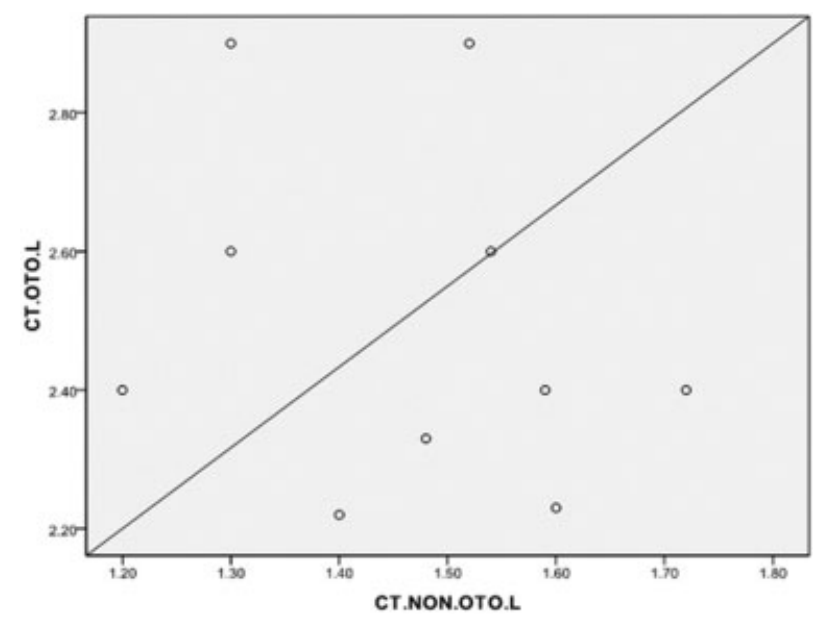

Fig. 7 Graph showing (Scatter dot) HRCT length between stapes head and facial nerve in otosclerosis and non-otosclerosis patients.

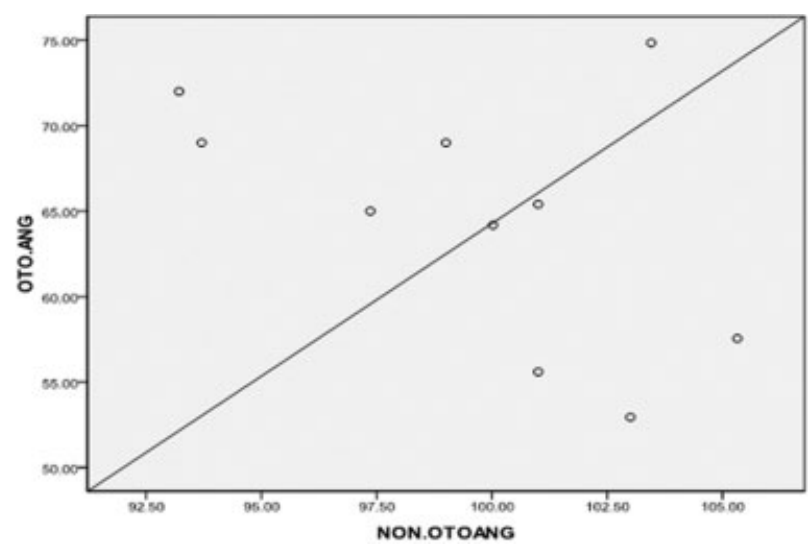

Fig. 8 Graph showing (Scatter dot) angle subtended by stapes with promontory in otosclerosis and non-otosclerosis patients.

radiological sign in the diagnosis of otosclerosis. The normal non-protruding middle portion of the facial canal runs superior to the oval window and inferior to the lateral SCC. Only $1 \mathrm{~mm}$ of bone separates the tympanic segment of the facial nerve canal from the vestibule. ${ }^{5}$ 
In a study by Zhu F. et al, the distance between head of stapes and facial nerve is $1.18( \pm 0.42 \mathrm{~mm}) .{ }^{14}$ In a study by Nicoleta Maru et al on intra temporal course and morphometric features of the facial nerve, the distance between the tympanic portion of the facial nerve and the stapes head is $1.58 \mathrm{~mm} .^{15}$

In our study, the mean distance between stapes head and facial nerve in non-otosclerotic control group is $1.46 \mathrm{~mm}$ ( $\pm 0.16 \mathrm{~mm}$ SD), which correlates with the literature. However, in otosclerosis we found that there is an increase in mean distance between the facial nerve and the stapes head (i.e., $2.49 \mathrm{~mm} \pm 0.24 \mathrm{~mm} \mathrm{SD}$ ). The mean angle subtended by the stapes with the promontory in otosclerotic patients is around $66.55^{\circ}$ when compared with the non-otosclerotic, for which it is around $99.70^{\circ}$.

\section{New Radiological Sign in Otosclerosis}

Imaging plays an important role in conductive deafness cases for anatomical detailing, differential diagnosis, surgical planning, and assessment of post-operative complications. ${ }^{8}$ High-resolution CT (HRCT) of the temporal bone using 1-mm (or less) thick sections is the modality of choice for assessment of the labyrinthine windows and cochlear capsules. ${ }^{16}$ High-resolution CT can detect an otosclerotic focus in up to $85 \%$ of patients with clinical otosclerosis. ${ }^{17}$ On CT, the detection of otosclerosis can be difficult to the inexperienced eye because the spread of the disease is often symmetrical. A small lucency at the fissula antefenestram is typical for otosclerosis, although diagnosis of otosclerosis is based on clinical and audiological criteria. CT scan is useful to differentiate Pagets' disease, superior semicircular canal dehiscence, middle ear malformations, congenital stapes fixation, and tympanosclerosis. ${ }^{18-20}$ The mean $\mathrm{HU}$ value alone in the area anterior to the oval window (A-OW) is not very reliable in early detection of otosclerosis. Distances between horizontal segment of facial nerve and stapes head, along with stapes-promontory angle in HRCT as described will further improve radiologic diagnosis of otosclerosis especially to differentiate other similar conditions.

The senior author suggested that, for this description of obliquity of stapes in otosclerosis, the term "Pisa" eluding to the notion of the leaning tower of Pisa is ubiquitous. The "Pisa" sign, as described here, can be used in preoperative CT assessment of otosclerosis without using specialized instruments like telemanipulator systems used in other studies. ${ }^{18}$

\section{Conclusion}

The obliquity of stapes increases the distance between the stapes and horizontal portion of facial nerve and also causes a change in the angle subtended by stapes with promontory in otosclerosis. This obliquity, referred to as the "Pisa" sign, has a diagnostic value as a new radiological sign in otosclerosis imaging. It helps to understand the torsional effect of otosclerosis on the ossicular chain and to analyze late complications and failures in stapes surgery and ways to avoid them. Our objective assessment and documentation of "Pisa" sign is a simple and reliable method, using existing CT scan technology and software.

\section{Financial Disclosure}

All financial and material support by MCV Memorial ENT Trust Hospital. The authors declare no conflict of interest.

\section{References}

1 Politzer A. Uber primare Erkrankung der Knocheren LabyrinthKapsel. Johrenheilk 1894;25:309-327

2 Anson BJ, Cauldwell EW, Bast TH. The fissula ante fenestram of the human otic capsule; developmental and normal adult structure. Ann Otol Rhinol Laryngol 1947;56(4):957-985

3 Bast TH. Development of otic capsule. Residual cartilages and defective ossification and their relation to otosclerotic foci. Arch Otolaryngol 1940;32:771-782

4 Anson BJ, Cauldwell EW, Bast TH. The fissula ante fenestram of the human otic capsule; aberrant form and contents. Ann Otol Rhinol Laryngol 1948;57(1):103-128

5 Swartz DJ, Loevener AL. Imaging of the Temporal bone. 4th ed. New York, USA: Thieme; 2009

6 Shea JJ Jr, Shea PF. Stapedectomy for otosclerosis. In: Glasscock ME, Gulya AJ, eds. Surgery of the ear. Ontario, Canada: Elsevier; 2003: 517-531

7 Ruedi L. Pathogenesis of otosclerosis. Arch Otolaryngol 1963; 78:469-477

8 Valvassori GE. Otodystrophies. In: Berrett A, Brunner S, Valvassori GE, eds. Modern Thin Section Tomography. Illinois, USA: Springfield; 1973:109-117

9 Valvassori GE. Radiologic diagnosis of cochlear otosclerosis. Laryngoscope 1965;75(10):1563-1571

10 Gulya AJ. Developmental anatomy of the temporal bone and skull base. In: Glasscock ME, Gulya AJ, eds. Surgery of the ear. Ontario, Canada: Elsevier; 2003:3-33

11 Iruela-Arispe ML, Vernon RB, Wu H, Jaenisch R, Sage EH. Type I collagen-deficient Mov-13 mice do not retain SPARC in the extracellular matrix: implications for fibroblast function. Dev Dyn 1996;207(2):171-183

12 Myers EN, Carrau RL, Eds. Operative otolaryngology: Head and Neck surgery. 2nd ed. Philadelphia: Elsevier; 2008

13 Kawase S, Naganawa S, Sone M, Ikeda M, Ishigaki T. Relationship between CT densitometry with a slice thickness of $0.5 \mathrm{~mm}$ and audiometry in otosclerosis. Eur Radiol 2006;16(6):1367-1373

14 Zhu F, Sun M, Zhang J, Sun D, Jiang Y. [Location of tympanic segment and mastoid segment of facial nerve and prevention of prosopoplegia in operations]. Lin Chung Er Bi Yan Hou Tou Jing Wai Ke Za Zhi 2011;25(7):314-316

15 Măru N, Cheiță AC, Mogoantă CA, Prejoianu B. Intratemporal course of the facial nerve: morphological, topographic and morphometric features. Rom J Morphol Embryol 2010;51(2):243-248

16 Purohit B, Hermans R, Op de Beeck K. Imaging in otosclerosis: A pictorial review. Insights Imaging 2014;5(2):245-252

17 Naumann IC, Porcellini B, Fisch U. Otosclerosis; incidence of positive findings on high resolution computed tomography and their correlation with audiological test data. Ann Otol Rhinol Laryngol 2005;114(9):709-716

18 Mafee MF, Henrikson GC, Valvassori GE et al. Use of CT in stapedial otosclerosis. Radiology 1985;156:709-714

19 Belden CJ, Weg N, Minor LB, Zinreich SJ. CT evaluation of bone dehiscence of the superior semicircular canal as a cause of sound and/or pressure induced vertigo. Radiology 2003;226:337-343

20 JuusoKujala. Modern Surgical treatment of otosclerosis [dissertation]. Helsinki, Finalnd: Helsinki University Printing House; 2009:24

21 Maier T, Strauss G, Bauer F, Grasser A, Hata N, Lueth TC. Distance measurement in middle ear surgery using a telemanipulator. Med Image Comput Comput Assist Interv 2011;14(Pt 1):41-48 